\title{
Ser médico: o imaginário coletivo de estudantes de medicina acerca da profissão de médico
}

\section{To be a doctor: the collective imaginary of medical students about their profession}

\author{
Maria Auxiliadora Motta Barreto ${ }^{1}$ \\ Carolina Nunes Reis ${ }^{2}$ \\ Isabela Borges de Miranda ${ }^{2}$ \\ Lívia Cristina Rocha Jardim ${ }^{2}$ \\ Marcela Pinto Teixeira ${ }^{2}$
}

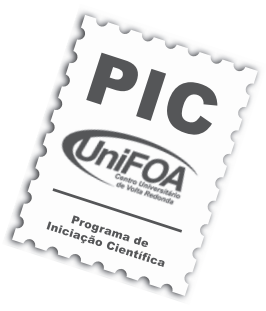

\section{Artigo \\ Original \\ Original \\ Paper}

\begin{abstract}
Palavras-chaves:
Imaginário coletivo

Desenhos-Estória com Tema
\end{abstract}

Estudantes de medicina

\section{Resumo}

O presente artigo é fruto de um Projeto de Iniciação Científica cujo objetivo é considerar o imaginário coletivo de jovens estudantes de medicina, acerca da profissão de médico. Participaram voluntariamente estudantes ingressantes no curso e no ciclo internato de medicina. Utilizou-se o procedimento de Desenhos-Estória com Tema, tendo sido analisados 59 Desenhos-Estória. O material clínico foi considerado visando à captação dos determinantes lógico-emocionais que sustentam o imaginário coletivo como conduta. Pode-se perceber uma visão bem diferenciada quanto ao ser médico nos dois grupos: conteúdos com intensa carga de altruísmo aos pacientes e dedicação à profissão foram detalhados pelos primeiro anistas, e preocupação pela escolha da especialidade e ambição financeira pelos ingressantes do internato. Em ambos os grupos, encontramos a dificuldade de escolher e definir quem ser quando se formar, e a falta de ênfase na relação médico-paciente.. A partir dos desenhos-estória, foram destacados alguns campos psicológicos não conscientes: dualidade, idealização e o outro.

\section{Abstract}

This article is the result of an undergraduate student scientific program whose goal is to consider the collective imaginary of young medical students about the medical practice. As subject of this study we collected data from students at the beginning of medical practice along the medical school and internship cycle who voluntarily agreed to participate after the invitation. The procedure adopted was stimulating the subjects to draw stories with a theme, and it was used to analyze 59-story designs. The clinical material was considered in order to capture the logical and emotional factors that support the collective imaginary as a physicist.. We could be seen two different profile of what is to be a doctor: one showing intensive altruism and care to the patients together with dedication to the profession, and another concerning the choice of specialty and financial ambition by entering in the internship. In both groups, we find the difficulty in choosing the specialty after graduation, and the lack of emphasis on the doctorpatient relationship. From the drawings' stories, were posted some unconscious psychological fields, duality, idealization and the other.
Key words:

Collective imaginary

Draw Stories with a

Theme

Medical students 


\section{Introdução}

O presente artigo é fruto de um Projeto de Iniciação Científica cujo objetivo é considerar o imaginário coletivo de jovens estudantes de medicina acerca da profissão de médico. Foram considerados ingressantes na graduação em medicina e no ciclo internato, de uma escola médica do interior do Estado do Rio de Janeiro.

Partimos do princípio que a escolha profissional está diretamente relacionada ao estilo de vida do indivíduo e é determinante da satisfação laboral e pessoal. Com a atuação profissional, vão se consolidando as práticas individuais e coletivas da profissão e estas são influenciadas pelo imaginário coletivo e se mantém determinantes da práxis.

O trabalho é uma atividade natural, que promove o desenvolvimento e a manutenção da saúde do homem, mas também é uma mercadoria comercial, uma atividade criada pela sociedade que impõe gasto de energia física e mental. Assim, o trabalho pode ser observado como fenômeno de grande complexidade, que acompanha inúmeras mudanças da vida contemporânea e que vem sofrendo diversas modificações ao longo do século (Barreto e Vaisberg, 2007) ${ }^{1}$. Considerando-o como uma parte do viver emocional do ser humano, podemos enfatizar a escolha profissional, neste caso, a escolha pela profissão de médico, como um de seus pontos críticos.

O mercado de trabalho da área de saúde vem sofrendo constante desvalorização, tornando-se cada vez menos atraente aos jovens que estão na iminência de integrá-lo, apesar de ainda preservar o status da profissão, mais do que muitas outras. A escolha pela medicina, ainda uma profissão conceituada como de grande sucesso, resulta em consequências durante o ingresso no mercado de trabalho e durante o exercício da atividade profissional em si, o que já justifica um estudo acerca da representação que os estudantes que a escolhem têm dela.

Além disso, como docente e discentes de um curso de medicina, observamos algumas diferenças entre a postura dos estudantes e suas verbalizações, daquilo que é preconizado nas Diretrizes Curriculares Nacionais da graduação em medicina
Art. $3^{\circ} \mathrm{O}$ Curso de Graduação em Medicina tem como perfil do formando egresso/profissional o médico, com formação generalista, humanista, crítica e reflexiva, capacitado a atuar, pautado em princípios éticos, no processo de saúde-doença em seus diferentes níveis de atenção, com ações de promoção, prevenção, recuperação e reabilitação à saúde, na perspectiva da integralidade da assistência, com senso de responsabilidade social e compromisso com a cidadania, como promotor da saúde integral do ser humano (Diretrizes Curriculares Nacionais do Ministério da Educação, 2001)²

As diferenças entre o que é preconizado e o que é compreendido e representado despertam a necessidade de atuar de forma preventiva junto aos jovens que fazem parte dessa realidade. Os estudantes, frequentemente, encontram dúvidas, insegurança, sentimentos que podem prejudicar, sobremaneira, o desempenho profissional de quem lida com a vida humana.

Sendo a escolha profissional influenciada pelo estilo de vida do jovem que escolhe, permeando tanto sua possibilidade de satisfação laboral como a pessoal (Barreto, 2000)8, escolhemos considerar a dramática do viver adolescente no que se refere à escolha da profissão de médico, utilizando os princípios winnicottianos (Winnicott, 1975)9 por formularem uma teoria próxima do acontecer concreto, da realidade. Utilizamos, aqui, a visão blegeriana (1963)3 que discute a importância de se considerar as condições concretas na qual um fenômeno ocorre. A escolha profissional corresponde a uma conduta humana e o que se aplica às condutas, aplica-se também às escolhas, sendo estas influenciadas por fatores pessoais e sociais. Os jovens futuros médicos estão intrinsecamente ligados à sua escolha profissional.

Baseando-nos na ordenação de campo psicológico proposta por Bleger (1975)6, segundo a elaboração que faz das contribuições de Politzer (1928)7, enfatizamos que a dramática humana é forjada na relação com o outro (Barreto e Vaisberg, 2007) ${ }^{1}$ e em conjunto com a coletividade. Dessa forma, julgamos que as inúmeras dificuldades de adaptação, ao longo dos anos de formação médica, incrementam a necessidade de compreender o imaginário coletivo de jovens que fazem essa escolha profissional. 


\section{Metodologia}

A pesquisa foi realizada no ano de 2009 com estudantes que foram escolhidos por estarem ingressando no curso ou no ciclo internato de medicina. Estes pertencem à classe média ou alta, estão cursando graduação em medicina em uma escola médica no interior do estado do Rio de Janeiro e dependem financeiramente dos pais, normalmente, até o final da graduação.

Baseando-nos na ideia de Bleger (1963)3 de que o homem é um ser essencialmente social e considerando que cada pessoa expressa sua conduta em âmbito individual e coletivo, abordamos os estudantes de medicina enquanto representantes de uma coletividade. Assim, a pesquisa foi conduzida como um processo de investigação psicanalítica, durante o qual fizemos o uso de associações livres e atenção flutuante como aspectos constitutivos do método transferindo-os, com determinados ajustes, da clínica para a pesquisa.

O grupo, composto por aproximadamente 120 alunos, ingressantes na graduação e no internato, constitui um meio que facilita o acesso ao imaginário coletivo e que nos comunica a concepção sobre quem escolhe medicina.

Do ponto de vista dramático, abordamos a conduta coletiva a partir de sua singularidade e dos coletivos aos quais pertence. O imaginário coletivo, nessa perspectiva, pode ser entendido como o locus transicional que fundamenta e permeia as ideias, os sentimentos e as ações de uma pessoalidade coletiva. No espaço transicional referido por Winnicott (1967/1975)9 é que encontramos o real significado de pensamentos, sentimentos e ações humanos.

Foram distribuídas folhas de papel sulfite A4 e solicitado aos alunos que desenhassem um(a) médico(a) da seguinte forma: "Desenhe um(a) médico(a) e, depois, escreva uma estória sobre ele(a) no verso da folha. Pedimos para não assinar a folha, mas colocar sua idade e sexo."

Utilizamos, assim, o procedimento de Desenhos-Estória com Tema, nos moldes desenvolvidos por Aiello-Vaisberg (2004)4 e por Trinca (1987)5, para investigação de imaginários coletivos, como recurso de abordagem para temas de difícil acesso, que não estão no campo consciente e/ou suscitam emoções indesejáveis.

\section{Resultados}

Por meio da atividade realizada com os alunos de medicina, foram obtidos 59 desenhos-estórias, sendo 51 dos primeiro-anistas e os demais dos alunos do internato. Durante a realização do procedimento, percebemos uma maior disponibilidade e interesse por parte dos primeiro anistas, o que justifica sua maioria neste trabalho.

$\mathrm{Na}$ análise dos Desenhos-Estória com Tema, percebemos uma predominância de alguns campos psicológicos não conscientes $\mathrm{e}$ dentre eles destacamos:

\section{Dualidade}

O médico é apresentado como que à mercê de indecisão, encarando a escolha da especialidade e os papeis pessoal e profissional como antagônicos e dificilmente integrados. Por exemplo, nos desenhos que expressaram a mistura do papel de mãe e médica pediatra, na dicotomia entre a teoria e a prática, na confusão entre o que seria um hospital e um local de lazer, na diferença entre especialidades, na preocupação com o futuro, etc.

\section{Idealização}

O médico aparece como único responsável pela saúde e bem-estar do paciente e a medicina como verdade absoluta. É aquele capaz de solucionar todos os problemas, incansável e detentor do conhecimento sobre "cura para todo mal". Por exemplo, na consideração da atuação profissional como "se vê nos livros", na ênfase no aprendizado teórico, na figura do médico como "dono da verdade", na substituição do jaleco pela capa de um super-herói, na representação do local de trabalho como local de lazer, ou no preconceito e o imaginário familiar de que o diploma de médico é, por si, sinônimo de sucesso profissional, retratando afastamento da realidade a que são/serão submetidos.

\section{O outro}

Diz respeito às produções em que se expressam claramente tendências a considerar o outro, o paciente, como figura central na prática profissional, também num nível ideal, mas que não se referem a ele, quer seja por não colocá-lo no desenho, quer seja por colocá-lo distante do médico. 
Nota-se que, em várias situações, o paciente é referenciado, mas sem ser efetivamente representado. Por exemplo, a existência de uma maca onde o paciente deveria ser examinado, porém o mesmo não está desenhado. Há ainda situações que não há nenhuma referência ao outro, demonstrando uma dissociação da relação médico-paciente.

Através da análise desses campos psicológicos, notamos uma visão bem diferenciada quanto ao ser médico: enquanto os primeiro anistas detalharam conteúdos com intensa carga de altruísmo aos pacientes e dedicação à profissão, os ingressantes do internato demonstraram uma grande preocupação pela escolha da especialidade e ambição financeira.

Em ambos os grupos, encontramos a dificuldade de escolher e definir quem ser quando se formar, e a falta de ênfase na relação médicopaciente. Chamam a atenção diferenças quanto às representações dos primeiro e nono anistas, em que os iniciantes apresentam-se mais altruístas e os últimos, mais individualistas.

\section{Conclusões}

A análise dos Desenhos-Estória com Tema nos leva a considerar que a substituição das representações - que os alunos já trazem consigo - por outras, transmitidas durante o curso, não são suficientes para a formação do profissional médico, nos moldes das DCN's preconizadas.

É preciso considerar os aspectos afetivos e emocionais inconscientes que dirigem a imaginada atitude profissional, destacando que, nesta pequena amostra, já se mostram tendenciosos em encarar a medicina como negócio, onipotência e independente do paciente.

Se esses futuros profissionais possuem concepções, a priori, desintegradas e idealizadas, é compreensível que o ambiente próximo do jovem que escolhe a medicina também encare a questão dessa forma.

Encarada assim, a opção pela profissão e a formação profissional deixam de ser momentos integrados e passam a ser um sintoma de problema que impede a expressão do self, acarretando diversas desadaptações.

\section{Referências}

1- BARRETO, M.A.M. \& VAISBERG, T.M.J. Escolha Profissional e Dramática do Viver Adolescente. Vol. 19, $\mathrm{n}^{\circ}$ 1, Psicologia e Sociedade, 2007.

2- CONSELHO NACIONAL DE EDUCAÇÃO. Diretrizes Curriculares Nacionais do Ministério da Educação. Câmara de Educação Superior. Resolução CNE/CES 4/2001. Diário Oficial da União, Brasília, 9 nov. 2001. Seção 1, p. 38. Disponível em: http://portal.mec.gov.br/cne/arquivos/pdf/ CES04.pdf Acessado em: 23 nov. 2009.

3- BLEGER, J. Psicologia de la conduta. Buenos Aires, Argentina: Paidós, 1963.

4- AIELLO-VAISBERG, T. M. J. Ser e fazer: Enquadres diferenciados na clínica winnicottiana. São Paulo, SP: Idéías \& Letras, 2004.

5- TRINCA, W. Investigação clínica da personalidade - $O$ desenho livre como estímulo da percepção temática. São Paulo, SP: EPU, 1987.

6- BLEGER, J. Temas de Psicologia. Buenos Aires: Nueva Visión, 1975.

7- POLITZER, G. Crítica de los fundamentos de la Psicologia. Madrid, España: Nueva Biblioteca, 1929.

8- BARRETO, M. A. M. A importância de uma escolha profissional adequada para a realização pessoal dos indivíduos: Algumas considerações. Revista Ciências da Educação, 2(3), 177-185, nov/2000.

9- WINNICOTT, D. W. A localização da experiência cultural. In D.W. Winnicott. O Brincar e a realidade (pp. 133-143). Rio de Janeiro, RJ: Imago, (1967)1975.

Endereço para Correspondência:

Maria Auxiliadora Motta Barreto

maria.barreto@foa.org.br

Centro Universitário de Volta Redonda

Campus Três Poços

Av. Paulo Erlei Alves Abrantes, $n^{\circ} 1325$,

Três Poços - Volta Redonda / RJ

CEP: $27240-560$

Informações bibliográficas:

Conforme a NBR 6023:2002 da Associação Brasileira de Normas Técnicas (ABNT), este texto científico publicado em periódico eletrônico deve ser citado da seguinte forma: BARRETO, Maria Auxiliadora Motta; REIS, Carolina Nunes; MIRANDA, Isabela Borges de; JARDIM, Lívia Cristina Rocha; TEIXEIRA Marcela Pinto. Ser médico: o imaginário coletivo de estudantes de medicina acerca da profissão de médico. Cadernos UniFOA. Volta Redonda, ano IV, n. 11, dezembro 2009. Disponível em: <http://www. unifoa.edu.br/cadernos/edicao/11/73.pdf $>$ 